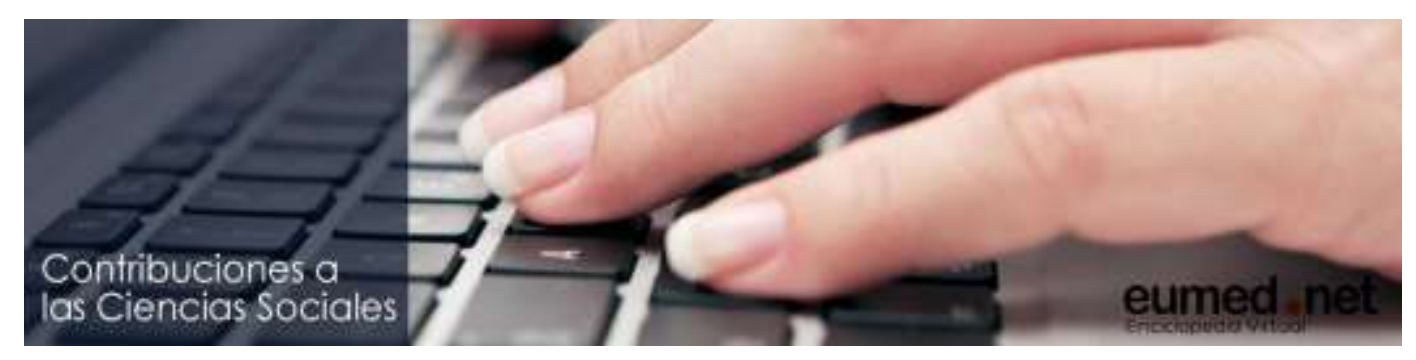

Abril 2020 - ISSN: 1988-7833

\title{
RISCO, COMPORTAMENTO DOS TRABALHADORES E ACIDENTES DE TRABALHO EM UMA CONSTRUTORA ESTABELECIDA NA CIDADE DE REDENÇÃO, PA, BRASIL
}

\author{
Hélio Raymundo Ferreira Filho' \\ helio.ferreira@uepa.br \\ Universidade do Estado do Pará - UEPA \\ Nayara Cristina Ramos ${ }^{2}$ \\ eng cristina@outlook.com \\ Universidade do Estado do Pará - UEPA \\ Rayanne da Silva e Silva Castro ${ }^{3}$ \\ rayanne_14silva@hotmail.com \\ Universidade Norte do Paraná -
}

UNOPAR

Para citar este artículo puede utilizar el siguiente formato:

Hélio Raymundo Ferreira Filho, Nayara Cristina Ramos y Rayanne da Silva e Silva Castro (2020): "Risco, comportamento dos trabalhadores e acidentes de trabalho em uma construtora estabelecida na cidade de redenção, PA, Brasil", Revista Contribuciones a las Ciencias Sociales, (abril 2020). En línea:

https://www.eumed.net/rev/cccss/2020/04/comportamento-trabalhadores-acidentes.html http://hdl.handle.net/20.500.11763/cccss2004comportamento-trabalhadores-acidentes

Resumo

Os acidentes de trabalho têm apresentado números preocupantes de mortes, e os setores de geração e distribuição de energia elétrica e telecomunicações concentram as 20 atividades econômicas com os maiores índices. Nas atividades de construção, as ocorrências são mais acentuadas devido ao risco inerente à área, por isso requerem atenção. Este estudo visa identificar e compreender os comportamentos de risco adotados por colaboradores de uma construtora estabelecida no estado do Pará que trabalham na construção de redes de energia elétrica em zona rural, bem como sua influência nos acidentes. Considerando fatores de risco, questões psicológicas e comportamento humano, a pesquisa, de natureza aplicada associada a abordagens qualitativa, quantitativa e de Estudo de Caso, analisa dados advindos de fatos locais e problemas pessoais reunidos via relatos e perfil dos trabalhadores. Os resultados indicam que os fatores promotores de acidentes são oriundos principalmente do trabalho sem EPI (Equipamento de Proteção Individual) e sob efeito de bebida alcoólica.

Palavras-chave: fatores de risco; qualidade de vida no trabalho; desempenho no trabalho.

Abstract

\footnotetext{
${ }^{1}$ Doutor em Ciências de Gestão pela Université Pierre Mendès-France - UPMF, Mestre em Sistemas de Informação pela Université Pierre Mendès-France - UPMF, Mestre em Tecnologia da Informação pela Nottingham University, Engenheiro Eletricista pela Universidade Federal do Pará (UFPA), Professor Adjunto IV do curso de Engenharia de Produção e do Programa de Mestrado em Ciências Ambientais - PPGCA, da Universidade do Estado do Pará (UEPA).

2 Mestre em Ciências Ambientais pela Universidade do Estado do Pará - UEPA, Especialista em Engenharia de Produção pelo Centro Universitário Internacional - UNINTER e em Engenharia de Segurança do Trabalho pelo IESCFAG, Engenheira de Produção pela Universidade do Estado do Pará - UEPA. Servidora da Secretaria de Estado de Saúde do Estado do Pará.

3 Especialista em Gestão da Produção de Bens e Serviços pela Universidade Norte do Paraná, Engenheira de Produção pela Universidade do Estado do Pará, atua como coordenadora administrativa na IENEC em Viana/MA.
} 
Occupational accidents have presented worrying numbers of deaths, and the sectors of generation and distribution of electricity and telecommunications concentrate the 20 economic activities with the highest rates. In the construction activities, the occurrences are more accentuated due to the inherent risk of the area, so they require attention. This study aims to identify and understand the risk behaviors adopted by employees of a construction company in the state of Pará that work on the construction of electric power networks in rural areas, as well as their influence on accidents. Considering risk factors, psychological issues and human behavior, the research, of an applied nature associated with qualitative, quantitative and case study approaches, analyzes data from local facts and personal problems gathered through reports and profile of workers. The results indicate that the factors promoting accidents occur mainly from work without PPE (Personal Protective Equipment) and under the effect of alcoholic beverage.

Keywords: risk factors; quality of work life; job performance.

Resumen

Los accidentes de trabajo han presentado números preocupantes de muertes, y los sectores que generan y distribuyen la energía eléctrica y las telecomunicaciones concentran las 20 actividades económicas con los mayores índices. En las actividades de construcción, las ocurrencias son más acentuadas debido al risco inherente al área, por eso requieren atención. Este estudio visa identificar y comprender los comportamientos de risco adoptados por colaboradores de una constructora del estado de Pará que trabajan en la construcción de redes de energía eléctrica en zona rural, bien como su influencia en los accidentes. Considerando factores de risco, cuestiones psicológicas y comportamiento humano, la pesquisa, de naturaleza aplicada asociada a enfoque cualitativo, cuantitativo y de Estudio de Caso, analiza datos derivados de hechos locales y problemas personales reunidos via relatos y perfil de los trabajadores. Los resultados indican que los factores promotores de accidentes son originados principalmente del trabajo sin EPI (Equipos de Protección Individual) y bajo efecto de bebida alcohólica.

Palabras-clave: factores de riesco; cualidad de vida en el trabajo; desempeño en el trabajo.

\section{Introdução}

Acidentes no trabalho vêm sendo o foco de estudos em diferentes campos do conhecimento e podem ser caracterizados de diferentes formas. É de ampla aceitação o conceito que entende trabalho como atividades instrumentais que visam gerar recursos ou condições para suporte da vida individual e familiar, que têm no seu centro a produção de bens manufaturados e/ou serviços, ou ainda no sentido subjetivo como dignificação e outros aspectos de ordem afetiva (ANDRADE; OLIVEIRA; HALTFIEL, 2017; SZABO JUNIOR, 2018).

O ser humano é um indivíduo passível de falha e executa suas atividades de trabalho conforme sua tomada de decisão nem sempre acertada, assumindo com frequência riscos muitas vezes associados aos fatores indutores de comportamento inadequado. Dessa forma, pode provocar acidentes em decorrência de algum desequilíbrio relacionado, por exemplo, a problemas familiares, financeiros, de saúde, de excesso de confiança nas suas habilidades e competências associadas a muito tempo de atuação e conhecimento da área de trabalho.

Os acidentes de trabalho têm apresentado números preocupantes de mortes todos os anos. Segundo a Organização Internacional do Trabalho (OIT, 2013), 2,02 milhões de pessoas morrem por ano devido a doenças relacionadas ao trabalho e 321 mil pessoas morrem por consequência de acidentes no trabalho. Isso significa que, no mundo, a cada 15 segundos, 115 trabalhadores sofrem um acidente laboral e um trabalhador morre devido a acidentes ou doenças relacionadas ao trabalho.

$\mathrm{Na}$ indústria de construção, os acidentes de trabalho têm mantido uma participação relativamente alta no cálculo geral dos casos registrados no Brasil. Segundo Nascimento e Salim (2018), os riscos de acidentes são mais acentuados em atividades de construção, por isso requerem condutas pontuais e comportamentos adequados.

Entretanto, mesmo existindo uma acentuada predisposição para a ocorrência de acidentes nesse ramo de trabalho, percebe-se que, com o passar do tempo, as atividades de risco 
tornam-se algo banal para o trabalhador, e suas ações passam a ser executadas automaticamente, provocando momentos propícios para esse tipo de acidente.

De acordo com o Departamento Intersindical de Estatística e Estudos Socioeconômicos (DIEESE, 2016), no Anuário da saúde do trabalhador 2015, o número de acidentes de trabalho do ano de 2013 em obras para a geração e a distribuição de energia elétrica e de telecomunicações situa esses setores entre as 20 atividades econômicas com os maiores números de acidentes de trabalho.

O mesmo órgão publicou em 2017 a classificação das 20 ocupações com mais desligamentos por óbito decorrente de acidente típico em 2015, mostrando que a função de eletricista de instalações tem a assustadora taxa de 7 mortes a cada 100 mil vínculos empregatícios, o que evidencia um problema quanto à banalização do cuidado adequado com a vida desses trabalhadores (DIEESE, 2017).

Dado esse contexto, este estudo recorre a uma construtora do estado do Pará cujos índices de acidente de trabalho são alarmantes. Trata-se de uma empresa de pequeno porte que iniciou suas atividades em 2006, prestando serviços nas áreas de construção civil, paisagismo, manutenção, limpeza e coleta de resíduos não perigosos e locação de caminhões munck.

Em 2012, a empresa intensificou a atividade de construção de eletrificação rural por meio do Programa Federal Luz para Todos, com atuação na zona rural do município de Conceição do Araguaia, no estado do Pará, e passou a se dedicar exclusivamente à construção e à manutenção de estações e redes de energia elétrica na referida cidade, chegando a abranger atividades em todo o estado.

Tendo em vista sua meta de zero acidente por ano, o número de acidentes ocorridos na construtora desde o início de sua atuação é expressivo, totalizando sete casos, entre os quais seis com necessidade de afastamentos e um óbito. Mediante tal realidade, a problemática deste estudo consiste em compreender os comportamentos de risco adotados pelos trabalhadores da referida construtora que executam atividades relacionadas à construção de redes de energia elétrica em zona rural que culminaram em acidentes de trabalho.

O objetivo da pesquisa, portanto, é identificar os comportamentos adotados pelos trabalhadores da construtora que contribuíram para acidentes de trabalho. Os comportamentos observados são aqueles adotados durante as atividades laborais, assim como o reflexo das questões psicológicas e familiares sobre esses comportamentos.

Segundo o Ministério da Previdência (BRASIL, 2012a), entre os acidentes de trabalho mais frequentes no Brasil, destacam-se os que resultam em fraturas, luxações, amputações e outros ferimentos, seguidos pelos acidentes que provocaram Lesões por Esforços Repetitivos (LER) e Distúrbios Osteomusculares Relacionados ao Trabalho (DORT).

São citados em terceiro lugar os transtornos mentais e comportamentais, como episódios depressivos, estresse e ansiedade, entendidos como problemas de solução mais complexa (BRASIL, 2012b). Ainda assim, os aspectos mais abordados são os técnicos, ficando em segundo plano os fatores de risco, principalmente aqueles assumidos pelo trabalhador como os motivos que os leva a assumir riscos.

Vale salientar a importância do estudo do comportamento humano, uma vez que este exerce influência direta na performance das organizações, pois está associado à prevenção e ao controle de perdas que colaboram para a melhoria da qualidade de vida dos trabalhadores, assim como das demais partes afetadas (BENEVENUTO et al., 2013; SILVA et al., 2017).

A Lei n. 8.213, de 24 de julho de 1991 (BRASIL, 1991), nos artigos 19 e 20, afirma que acidente de trabalho é aquele que ocorre durante a execução de serviço para determinada empresa que provoque lesão corporal ou prejudique o funcionamento dos órgãos ou sentidos do trabalhador, resultando em morte, perda ou redução da capacidade para o trabalho, seja permanentemente ou por determinado período. A lei também considera acidente as doenças profissionais que são típicas de determinadas atividades e aquelas desenvolvidas em função das condições submetidas ao trabalhador.

O Ministério da Previdência Social considera a definição da Lei n. 8.213/1991, acrescentando como acidentes de trabalho aqueles que tenham contribuído para a ocorrência de lesão, como acidentes sofridos no local e no horário de trabalho, a caminho do trabalho ou voltando para a residência, bem como as doenças adquiridas por eventual contaminação durante a execução de suas atividades (BRASIL, 1991). 
De modo geral, as diferentes perspectivas concordam que acidentes de trabalho são todas as lesões, físicas e mentais, provocadas no desenvolvimento das atividades no ambiente de trabalho, gerando sofrimentos para as pessoas. Para Simonelli et al. (2016), a ocorrência dos acidentes está estritamente ligada à atuação conjunta de riscos ambientais, atividade profissional e dependência do indivíduo, fatores relacionados ao tempo de execução, à exposição e à tendência de ser afetado.

Costa e Lanzarini (2011) também apresentam três causas de acidentes:

a. Fator de insegurança pessoal: além de abranger os estados físico e mental, está ligado também aos estados emocional e social, que influenciam negativamente no trabalho e proporcionam as condições de riscos que os trabalhadores trazem.

b. Ato inseguro: expõe as condições que provocam acidente e está ligado ao comportamento do trabalhador, como sua curiosidade, pressa e distração.

c. Condições inseguras: têm a ver com o posicionamento da empresa quanto à segurança a ser oferecida e à falta de manutenção de equipamentos e máquinas.

Bedin (2010) atribui à causa dos acidentes a falta de informações aos dois indivíduos principais, o empregador e o empregado. No caso do empregado, isso acontece quando não há transmissão de informações referentes à forma correta de realizar uma atividade, ou seja, por falta de treinamento. No caso do empregador, quando há custos de um acidente por ignorância, o que significa que ele se importa apenas com o desembolso referente ao investimento em prevenção e segurança.

Além de citar a falta de treinamento para o empregado como causa de acidentes, Wictor e Sievers (2012) consideram a falta de interesse pelo trabalho, a incapacidade física para o trabalho, o excesso de confiança devido ao longo período de experiência e a displicência em situações arriscadas.

Há, portanto, necessidade de conhecer de maneira contínua as causas dos acidentes de trabalho, pois existem fatores que provocam danos que perpassam as perdas de cunho material, físico, temporal e financeiro, uma vez que abordam um material insubstituível constituído pela vida humana.

Acidentes como esses causam perdas para todos, o trabalhador, a empresa e a nação, devido à sobrecarga do sistema de proteção social. Para evitá-los, é crucial conhecer e trabalhar o comportamento dos colaboradores, entendendo que essa é uma prática possível e decisiva para a diminuição dos números de acidentes (BLEY, 2011; BARSANO, BARBOSA, 2018).

No que se refere ao comportamento de risco, enquanto Bley (2011) afirma que se trata do conjunto das relações entre os organismos e o meio em que atuam, Nascimento et al. (2015); Mattos e Másculo (2019), apregoam que a ocorrência de um acidente se deve à influência desses organismos sobre todos os aspectos envolvidos, sendo esta ocorrência determinada por múltiplas causas internas e externas.

Areosa; Veloso Neto; Arezes (2012) citam algumas situações que evidenciam atos que refletem nos comportamentos de risco em um ambiente de trabalho, como agir sem autorização da gerência, dirigir de forma perigosa, não usar Equipamentos de Proteção Individual (EPI) ou Equipamentos de Proteção Coletiva (EPC), usar drogas e/ou consumir bebidas alcoólicas no local de trabalho, não obedecer às normas de segurança e não corrigir um ato insensato.

Intempéries cotidianas desestabilizam o psicológico do trabalhador, assim como as dificuldades enfrentadas nas diferentes áreas da vida pessoal, como saúde, família e dinheiro, e problemas mais ou menos pontuais, como alimentação inadequada ou insuficiente, longas distâncias do trabalho para casa e relações interpessoais ruins.

Estudos mais recentes (Bendassolli; Gondim, 2014; Santos et al., 2017) apontam que a baixa autoestima do trabalhador, traduzida em um conjunto de sentimentos e pensamentos, no valor que dá a si próprio e em problemas emocionais, pode refletir em atitudes negativas que afetam o indivíduo no ambiente de trabalho, pois ele carrega consigo a carga emocional de seus problemas, o que contribui para a adoção de um comportamento de risco e, consequentemente, para um risco potencial de acidente.

Para Celich e Restelatto (2008), a desvalorização do trabalho impede que haja condição para desenvolver o autocuidado e a realização humana, contribuindo para uma baixa autoestima do colaborador que torna deficiente a prevenção de acidentes e a preservação de sua saúde. 
Como a prevenção é uma atitude de autocuidado, se o indivíduo não dá valor a sua vida, tem dificuldades de cuidar de si mesmo, usar EPI e atentar-se às normas de segurança.

Outra questão abordada por Scaldelai et al. (2012) é o chamado estado de piloto automático interno, que acontece em atividades repetitivas. O funcionário está executando a tarefa, mas sua mente está dispersa e desatenta, circunstância provocada por atividades que promovem exaustão ou fadiga, tornando lentos os reflexos e as respostas do organismo.

Os relacionamentos interpessoais no ambiente de trabalho também precisam ser observados. Silva e França (2011) afirmam que, quando há hostilidade nas relações de trabalho, o clima mais tenso pode provocar falhas e suscitar acidentes, enquanto um ambiente de trabalho motivador estimula os funcionários a serem mais comprometidos com a segurança, no âmbito individual e coletivo.

Mota (2015) acrescenta a esses motivos o excesso de confiança dos trabalhadores, que colocam sua vida e a dos demais parceiros de trabalho em risco por desconsiderar a possibilidade de um acidente acontecer. $\mathrm{O}$ excesso de autoconfiança, como já pontuado, gera risco de acidentes, geralmente cometidos por profissionais com vários anos de experiência.

Os problemas familiares também não devem ser ignorados. Para Scaldelai et al. (2012), a família é a maior fonte de motivação e valores individuais, por isso cabe à empresa incluir temas relacionados a ela nos seus programas de prevenção, não se restringindo às questões ocupacionais. Cabe ao empregador o papel de um agente de transformação pessoal, social e ambiental para o contratado.

Para prevenir acidentes de trabalho sob influência comportamental, deve-se, então, considerar todo o já referido conjunto de relações estabelecidas entre um organismo e o meio em que trabalha (BLEY, 2011). Dessa perspectiva, a alta gerência empregadora não deve ter foco apenas na produtividade e no lucro, mas, sim, na preocupação com a prevenção de acidentes (Scaldelai et al., 2012), cumprindo além dos requisitos mínimos exigidos na legislação e valorizando também a saúde do servidor, com aperfeiçoamento contínuo, investimento em equipamento de segurança de qualidade e em procedimentos seguros para o trabalho.

Entretanto, além dos fatores internos, o cenário externo (social, político, econômico) em que se encaixa o trabalhador também pode gerar insegurança e preocupações que o distraiam, colocando-o em situação de risco. No que se refere à economia, os acidentes podem resultar em perdas para empregadores, trabalhadores e mercado (BARBOSA FILHO, 2019).

a. Perdas para os empregadores: indenizações aos trabalhadores e familiares, transporte, cuidados médicos, honorários advocatícios, encargos empregatícios e que se referem a infrações, saúde e segurança do trabalhador, danos aos equipamentos e materiais, além das perdas produtivas.

b. Perdas para os trabalhadores: diminuição da condição física e psíquica, dificuldade na reabilitação, parada da produção devido a afastamento, redução do rendimento familiar devido a afastamento do trabalho para cuidar do acidentado, redução da atenção dos demais trabalhadores em caso de ajuda à vítima.

c. Perdas para o mercado: responsabilidade civil por defeitos nos produtos comercializados (EPI e EPC), indenizações e penalidades por não cumprir acordos estabelecidos, rejeição do produto, devolução e reclamações do consumidor.

Os trabalhadores da construtora de eletrificação rural em estudo estão expostos diretamente a riscos elétricos perigosos, devido às condições insalubres de trabalho que incluem poeira, componentes de fauna e flora, entre outros citados no subitem 10.4.2 da NR 10 do Ministério do Trabalho e Emprego (Brasil, 1978b), por isso recebem um adicional ao seu salário. Pepplow (2010) explica que a maior preocupação nos setores elétricos e eletrônicos é o choque elétrico, um acidente de grande gravidade e frequência e com riscos expressivos em quase todas as suas atividades.

Portanto, compreende-se que acidentes de trabalho são ações motivadas por comportamentos inadequados para a segurança de trabalho, ações estas fruto de um conjunto de fatores internos e externos, ou seja, de relações entre o organismo e o meio em que trabalha. Estão entre os principais fatores problemas familiares, financeiros, alimentares e de dependência química lícita (álcool) ou não (drogas), relações interpessoais ruins no trabalho e descuido com autocuidado (não uso de EPI, excesso de confiança na execução da tarefa etc.).

\section{Método}


A elaboração de uma pesquisa requer um trabalho consciente e disciplinado por parte do pesquisador. A disciplina pode obtida com o rigor do método científico e a consciência surge da necessidade de encontrar respostas para os problemas que o profissional enfrenta em sua vida profissional.

A metodologia científica é um caminho que procura a verdade num processo de pesquisa, ou aquisição de conhecimento; um caminho que utiliza procedimentos científicos, critérios normativos e aceitos pela ciência (MICHEL, 2017).

A ciência busca soluções e respostas para os problemas do cotidiano. Um "problema" não significa necessariamente que algo esteja errado com uma situação atual que precisa ser consertada, ou mesmo revisada imediatamente. Um problema também pode indicar interesse em um problema em que encontrar as respostas certas pode ajudar a melhorar uma situação existente. Portanto, é proveitoso definir um problema como qualquer situação em que existe entre um estado ideal real e um desejado (SEKARAN; BOUGIE, 2016).

A literatura tradicional da metodologia de pesquisa referencia basicamente três tipos de pesquisa: Exploratórias, Descritivas e Explicativas (GIL, 2017; ACEVEDO e NOHARA, 2009).

A investigação exploratória é realizada quando o investigador não dispõe de informação prévia sobre a estrutura das relações envolvendo os fenômenos a serem analisados. Essa falta de conhecimento leva o investigador a procurar algum tipo de tendência ou padrão de comportamento que o leve a conclusões (BALASSIANO, BOTELHO; ZOUAIN, 2006).

Este estudo se caracteriza como uma pesquisa exploratória, uma vez que busca conhecer melhor um assunto ainda pouco explorado. Tem por objetivo proporcionar maior compreensão do fenômeno que está sendo investigado, permitindo assim que o pesquisador delineie de forma mais precisa o problema (HAIR JUNIOR et al., 2005).

\section{Participantes}

Como já mencionado, o objeto deste estudo foi uma empresa construtora de eletrificação rural, prestadora de serviço para o governo por intermédio do Programa Luz para Todos, que atua em todo o estado do Pará. Os sujeitos da pesquisa foram os 26 colaboradores do seu quadro funcional, constituído de eletricistas, motoristas, montadores de redes, auxiliares de montagem, operadores, cozinheiro, supervisor de campo, agentes administrativos e gestores (proprietários da empresa).

\section{Instrumentos}

Foram feitas observações in loco dos comportamentos e entrevistas estruturadas com perguntas fechadas e abertas aplicadas aos sujeitos da pesquisa, bem como a análise de documentos visando compreender os porquês dos comportamentos que expõem os trabalhadores a situações de risco durante suas atividades laborais.

\section{Procedimentos de coleta de dados e cuidados éticos}

A partir de uma abordagem qualitativa, este estudo busca reunir informações segundo a percepção dos indivíduos, bem como observar de forma coerente as evidências para a compreensão do ambiente em que se insere a problemática em questão. O perfil dos trabalhadores e os fatores internos e externos relacionados ao comportamento, por sua vez, requerem uma análise de ordem quantitativa.

A junção dessas abordagens permite entender as correlações existentes, observáveis diretamente (Sampieri, Collado, Lucio, 2013; Baptista; Campos, 2016), possibilitando, assim, uma análise mais consistente da influência dos comportamentos de risco adotados pelos trabalhadores.

De natureza aplicada (Klein et al., 2015), uma vez que pretende compreender como se dão as tomadas de decisão na busca por soluções do problema em tela e viabilizar uma aplicação prática, a pesquisa é caraterizada por fatos locais (atividades laborais) e expansão dos problemas pessoais (cotidiano).

Mobilizando técnicas características de Estudo de Caso, como observação direta e participante, artefatos físicos (Yin, 2015) e ferramentas para triangulação, foram coletadas informações das fontes empíricas, tendo como base as evidências qualitativas e quantitativas, que são repletas de variáveis subjetivas (MARTINS; MELLO; TURRIONI, 2014). Logo, optou-se por uma perspectiva descritiva para a análise dos fenômenos em âmbito real, a fim de descrevê-los de modo a compreender a realidade. 
Apenas os trabalhadores envolvidos com a construção das redes de eletrificação participaram efetivamente da pesquisa, e, por questões de ética e segurança de todos os profissionais, seus nomes foram preservados. Porém, para garantir a fidedignidade dos dados, os colaboradores mencionados nas análises estão identificados pelas iniciais de seus nomes (MO, AFS, GSL, WMF, JCS, JPA, LB, RP, WVS, JCA, RG, CD, GR, LCVS e GMSS).

Quadro 1 - Sistematização do processo de coleta e análise de dados

\begin{tabular}{|c|c|c|}
\hline Objetivos & Instrumentos de coleta & Análise \\
\hline $\begin{array}{l}\text { Identificar os comportamentos dos } \\
\text { trabalhadores que os levaram a uma situação de } \\
\text { risco. }\end{array}$ & 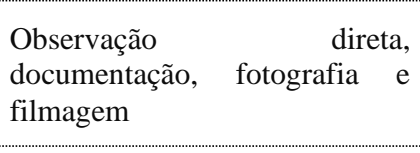 & $\begin{array}{l}\begin{array}{l}\text { Observação de fotos e } \\
\text { filmagens, } \\
\text { mensuração e descrição dos } \\
\text { tabulação, }\end{array} \\
\text { dados obtidos }\end{array}$ \\
\hline $\begin{array}{l}\text { Verificar os motivos dos comportamentos dos } \\
\text { trabalhadores que os expuseram a situações de } \\
\text { risco de acidentes. }\end{array}$ & 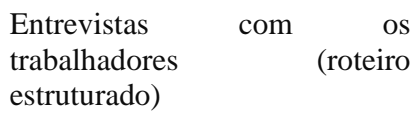 & $\begin{array}{l}\text { Tabulação, mensuração e } \\
\text { descrição dos dados obtidos }\end{array}$ \\
\hline $\begin{array}{l}\text { Averiguar junto aos gestores: a) atuação da } \\
\text { empresa, suas atividades e ambiente de } \\
\text { trabalho; } \\
\text { b) procedimentos de segurança de trabalho } \\
\text { adotados junto aos comportamentos de risco } \\
\text { dos trabalhadores; c) reflexos dos acidentes } \\
\text { sobre a gestão. }\end{array}$ & $\begin{array}{l}\text { Entrevistas com os gestores } \\
\text { (não estruturadas) }\end{array}$ & $\begin{array}{l}\text { Tabulação, mensuração e } \\
\text { descrição dos dados obtidos }\end{array}$ \\
\hline $\begin{array}{l}\text { Analisar a incidência dos acidentes que tiveram } \\
\text { como principais causas os comportamentos dos } \\
\text { trabalhadores que os expuseram ao risco. }\end{array}$ & $\begin{array}{l}\text { Documentação (data books de } \\
\text { segurança do trabalho da } \\
\text { empresa) }\end{array}$ & $\begin{array}{l}\text { Tabulação, mensuração e } \\
\text { descrição dos dados obtidos }\end{array}$ \\
\hline
\end{tabular}

\section{Fonte: Elaborado pelos autores, 2020}

\section{Procedimentos de análise de dados}

As atividades de coleta de dados começaram em agosto de 2013, com as análises dos registros, enquanto os dados empíricos foram levantados entre maio e outubro de 2014 . $\mathrm{Na}$ sequência, partiu-se para a sistematização e a organização desses dados. O Quadro 1 explicita esse processo.

Após a obtenção dos dados oriundos de documentações, observações diretas, entrevistas, registros fotográficos e vídeos, estes foram sistematizados e analisados para compreender a classificação das causas de acidentes (condições inseguras, atos inseguros e fator pessoal), identificar os comportamentos de risco e responder ao objetivo deste estudo.

\section{Discussão}

A empresa de eletrificação é uma prestadora de serviços do projeto Luz para Todos que se estrutura para realizar seus processos, uma vez que a maioria de suas atividades laborais acontecem em locais de difícil acesso e longe de centros urbanos. Não foi permitida a divulgação da razão social ou do nome fantasia da construtora, mas é possível apresentar algumas de suas características.

Segundo a NR 4 (Brasil, 1978a), a empresa tem classificação grau 4 de risco, devido ao tipo de atividades exercidas (em campo aberto, lugares distantes de cidades ou de pequenas comunidades, na maioria das vezes dentro de matas fechadas com difícil acesso). Em determinadas regiões, por conta de climas extremos, o trabalho só é possível em algumas estações do ano em que não há, por exemplo, chuvas intensas e alagamentos, altas temperaturas e baixa umidade. Raramente há comunicação via telefones e on-line.

De acordo com os gestores da construtora (LCVS e GMSS - comunicação pessoal, julho de 2019), os ambientes de trabalho exigem que as normas de segurança de trabalho sejam seguidas impreterivelmente e em todos os momentos, pois os trabalhadores estão mais vulneráveis a riscos de acidentes, de modo que são constantes os cuidados com:

a. exposição à radiação solar, por se executar atividades a céu aberto;

b. descargas elétricas, pois a incidência de queda de raios é comum e pode provocar, por exemplo, choque por indução e princípio de incêndio, resultando em graves acidentes;

c. postura inadequada, por se tratar de atividades que requerem intervenções manuais diretas, levantamento e transporte manual de materiais pesados; 
d. queda, por se trabalhar em pé sobre uma escada ou suspenso por plataformas móveis em alturas elevadas;

e. $\quad$ exposição a choques elétricos, por se tratar de construção que envolve eletricidade;

f. cortes, devido à necessidade de manuseio de materiais perfurantes e cortantes;

g. picadas de insetos e aracnídeos, porque, muitas vezes, o ambiente de trabalho é o hábitat de animais selvagens ou até mesmo peçonhentos.

Esses são cuidados fundamentais que cada trabalhador precisa ter, mas, ainda que seus comportamentos no ambiente de trabalho sejam supervisionados e cobrados pela empresa, a decisão primeira pela atitude adotada cabe ao colaborador. Mesmo que se considere justa causa executar suas atividades laborais sem utilizar EPI ou EPC, não há garantia de uso ou de uso adequado se o trabalhador resolver driblar as regras e normas.

Não seguir os procedimentos de segurança e prestar serviços à empresa sem condições físicas e psicológicas poderá custar a integridade física, a qualidade da saúde ou até mesmo a própria vida do colaborador. Trata-se de situações insalubres em que, se não aplicadas as normas de segurança, os próprios trabalhadores se expõem ao risco, o que infelizmente é uma postura identificada com frequência nesse setor de trabalho.

Na empresa laboratório deste estudo, esse tipo de prática foi facilmente percebido por meio de observações, registros fotográficos, documentos (advertências) e vídeos. Uma atitude muito observada, por exemplo, é a de trabalhadores escalando postes extremamente rápido e usando apenas as esporas (específicas para subir em postes) calçadas nos pés.

O cinto, instrumento de segurança que os impediria de despencar em caso de choque ou cãibras, não é utilizado e fica pendurado no ombro do trabalhador. Essa situação está registrada em um vídeo em que o supervisor local questiona "esse jeito que você subiu aí foi o certo?", tendo como resposta "é rapidinho, não tem perigo", o que evidencia desrespeito às normas de segurança.

O comportamento de risco é determinado por múltiplas causas internas e externas, por isso as entrevistas realizadas com os trabalhadores abordaram questões relacionadas a estado de saúde, estado psicológico, estado social, condições de trabalho e utilização de EPI. A percepção dos colaboradores está sistematizada no Quadro 2:

Quadro 2 - Sistematização das perguntas propostas e das respostas dos colaboradores quanto a suas ações ou atitudes

\begin{tabular}{|c|c|c|}
\hline Indagações sobre: & Parecer dos colaboradores & \multirow{2}{*}{$\begin{array}{l}\text { Justificativa do parecer } \\
\text { Não relacionada ao trabalho }\end{array}$} \\
\hline \multirow[b]{3}{*}{$\begin{array}{l}\text { Qualidade da saúde } \\
\text { (100\% disseram "em } \\
\text { bom estado", mas já } \\
\text { tiveram problemas no } \\
\text { passado }\end{array}$} & - 50\% há mais de cinco anos & \\
\hline & - 30,77\% há mais de um ano & Não relacionada ao trabalho \\
\hline & $\begin{array}{l}\text { - } 19,23 \% \text { entre seis meses e um } \\
\text { ano }\end{array}$ & $\begin{array}{l}\text { - } 30,77 \% \text { asseguram relação com o trabalho, } \\
\text { dificultando ou atrasando a execução das atividades } \\
\text { laborais } \\
-50 \% \text { já se afastaram das atividades para } \\
\text { recuperação }\end{array}$ \\
\hline \multirow[t]{2}{*}{$\begin{array}{l}\text { Uso de bebidas } \\
\text { alcoólicas }\end{array}$} & $\begin{array}{l}-50 \% \text { dos colaboradores } \\
\text { consomem }\end{array}$ & $\begin{array}{l}\text { - 19,23\% bebem somente em datas comemorativas } \\
\text { - 19,23\% mensalmente } \\
\text { - 61,54\% semanalmente }\end{array}$ \\
\hline & - 50\% não consomem & - \\
\hline \multirow{9}{*}{ Família } & \multirow{3}{*}{$\begin{array}{l}\text { Renda familiar } \\
\text { (residência) }\end{array}$} & - 38,46\% únicos responsáveis \\
\hline & & - 30,77\% apenas contribuem \\
\hline & & $\begin{array}{l}\text { - 30,77\% responsáveis apenas pelo suficiente } \\
\text { próprio sustento }\end{array}$ \\
\hline & \multirow{2}{*}{$\begin{array}{l}\text { Tempo e distâncias longas das } \\
\text { famílias }\end{array}$} & - $53,85 \%$ se preocupam demasiadamente \\
\hline & & $\begin{array}{l}\text { - } 46,15 \% \text { conseguem conviver com certa } \\
\text { tranquilidade }\end{array}$ \\
\hline & \multirow{3}{*}{$\begin{array}{l}\text { Preocupação } \\
\text { financeira a pais e } \\
\text { próximos }\end{array}$} & $\begin{array}{l}\text { - 34,61\% contribuem, mas consideram seus recursos } \\
\text { financeiros insuficientes para a ajuda necessária }\end{array}$ \\
\hline & & $-34,62 \%$ auxiliam quando podem \\
\hline & & $\begin{array}{l}\text { - 30,77\% não auxiliam e não têm esse tipo de } \\
\text { preocupação }\end{array}$ \\
\hline & $\begin{array}{l}\text { Preocupação com saúde de } \\
\text { familiares }\end{array}$ & $\begin{array}{l}\text { - 11,54\% enfrentam problemas graves de saúde na } \\
\text { família }\end{array}$ \\
\hline Problemas & Pouca preocupação & - 69,23\% não pensam nessas questões \\
\hline
\end{tabular}




\begin{tabular}{|c|c|c|}
\hline $\begin{array}{ll}\text { econômicos } & \text { ou } \\
\text { políticos } & \end{array}$ & & - 30,77\% dizem se afligir com essas questões \\
\hline \multirow{5}{*}{ Autoestima } & Receber críticas & $\begin{array}{l}\text { - 69,23\% raramente se ofendem com as críticas } \\
-30,77 \% \text { acham importante para melhorar }\end{array}$ \\
\hline & Ser aceito no grupo & $\begin{array}{l}\text { - 3,85\% fazem sacrifícios para agradar os outros } \\
-96,15 \% \text { não se sentem aceitos }\end{array}$ \\
\hline & $\begin{array}{l}\text { Exigir muito de si mesmo } \\
\text { (perfeccionismo) }\end{array}$ & $\begin{array}{l}\text { - 19,23\% se consideram perfeccionistas } \\
\text { - 30,77\% raramente exigem muito de si mesmos } \\
\text { - 3,85\% não se preocupam com isso } \\
\text { - 46,15\% não sabem responder }\end{array}$ \\
\hline & $\begin{array}{l}\text { Eficácia dos planos feitos para } \\
\text { sua vida }\end{array}$ & $\begin{array}{l}\text { - } 50 \% \text { se culpam quando seus planos não se } \\
\text { realizam e ficam mal por um tempo } \\
-3,85 \% \text { não se preocupam com isso } \\
-46,15 \% \text { não sabem responder }\end{array}$ \\
\hline & $\begin{array}{l}\text { Criar laços de amizade com os } \\
\text { colegas }\end{array}$ & $\begin{array}{l}\text { - } 92,31 \% \text { afirmam não evitar e pedir ajuda em } \\
\text { momento de dificuldade (sendo atendidos), mas não } \\
\text { têm laços de amizade } \\
-7,69 \% \text { firmaram laços de amizade fora do } \\
\text { ambiente de trabalho }\end{array}$ \\
\hline
\end{tabular}

Fonte: Elaborado pelos autores, 2020.

Quanto ao estado afetivo dos trabalhadores, todos responderam ter um bom relacionamento com seus familiares, afirmando não se reunir com os amigos ou se reunir raramente devido à falta de tempo, justificada pelo isolamento em zonas rurais por até 90 dias seguidos devido ao trabalho. Contudo, a maioria dos entrevistados percebe 0 ambiente e o processo de trabalho como bons, conforme apresentado no Quadro 3:

Quadro 3 - Sistematização das perguntas propostas e das respostas dos colaboradores quanto ao ambiente e ao processo de trabalho

\begin{tabular}{|c|c|c|c|}
\hline \multirow{4}{*}{$\begin{array}{l}\text { Ambiente } \\
\text { trabalho }\end{array}$} & \multirow{4}{*}{ de } & \multirow{2}{*}{$\begin{array}{l}\text { Motivador } \\
\text { Relacionamento }\end{array}$} & $\begin{array}{l}\text { - 69,23\% consideram o ambiente de trabalho motivador } \\
\text { - 30,77\% nunca pensam na questão, apenas trabalham }\end{array}$ \\
\hline & & & $\begin{array}{l}\text { - } 80,77 \% \text { afirmam não ter dificuldades com a chefia } \\
\text { - } 92,31 \% \text { afirmam ter bom relacionamento com os colegas de } \\
\text { trabalho }\end{array}$ \\
\hline & & Estado emocional & $\begin{array}{l}\text { - 100\% afirmam nunca sentir tristeza, chorar com frequência e não } \\
\text { pensar com clareza } \\
\text { - } 100 \% \text { não encontram dificuldades para realizar suas } \\
\text { atividades satisfatoriamente ou tomar decisões } \\
\text { - 96,15\% dizem ter interesse por assuntos e atividades } \\
\text { do trabalho } \\
\text { - } 3,85 \% \text { se sentem "incapazes de realizar algum papel útil em sua } \\
\text { vida" }\end{array}$ \\
\hline & & $\begin{array}{l}\text { Fatores que lhes } \\
\text { agradam no trabalho } \\
\text { (respostas em comum) }\end{array}$ & $\begin{array}{l}\text { - desafios no tipo de atividade executada } \\
\text { - relacionamento interpessoal no ambiente de trabalho } \\
\text { - o resultado do trabalho, a alegria de quem acende uma lâmpada } \\
\text { em casa pela primeira vez } \\
\text { - o espírito de equipe gerado pela convivência, decorrente da } \\
\text { divisão de ambientes como dormitórios e refeitórios (ambiente } \\
\text { alegre, com brincadeiras e piadas internas) } \\
\text { - trabalho em equipe, no qual um depende do outro para executar } \\
\text { as tarefas (o grupo atual em si) } \\
\text { - a constante mudança de local de trabalho }\end{array}$ \\
\hline \multirow{3}{*}{$\begin{array}{l}\text { Processo } \\
\text { produção }\end{array}$} & \multirow{3}{*}{ de } & $\begin{array}{l}\text { Construção da rede na } \\
\text { energia elétrica }\end{array}$ & $\begin{array}{l}-50 \% \text { se sentem fadigantes e acham o trabalho repetitivo } \\
-50 \% \text { percebem o trabalho apenas como muito cansativo }\end{array}$ \\
\hline & & $\begin{array}{l}\text { Equilíbrio emocional } \\
\text { (sentir nervoso) }\end{array}$ & $\begin{array}{l}\text { - 30,77\% declaram que sim } \\
\text { - 69,23\% não comentaram }\end{array}$ \\
\hline & & $\begin{array}{l}\text { Domínio da técnica de } \\
\text { trabalho }\end{array}$ & $\begin{array}{l}\text {-96,15\% se sentem seguros ao executar as atividades devido ao } \\
\text { tempo de experiência no trabalho } \\
\text { - } 80,78 \% \text { já exercem a profissão há mais de cinco anos }\end{array}$ \\
\hline
\end{tabular}




\begin{tabular}{|c|c|c|}
\hline & \multicolumn{2}{|c|}{ - 19,22\% têm pelo menos dois anos de atuação no ramo } \\
\hline $\begin{array}{l}\text { Treinamento antes de } \\
\text { iniciar as atividades }\end{array}$ & \multicolumn{2}{|c|}{$\begin{array}{l}\text { - 96,15\% recebem treinamento da empresa } \\
\text { - } 100 \% \text { recebem supervisão e acompanhamento frequente da } \\
\text { gestão durante a realização dos trabalhos e se sentem confortávei } \\
\text { no ambiente de trabalho }\end{array}$} \\
\hline \multirow[b]{3}{*}{ EPI } & \multicolumn{2}{|c|}{$\begin{array}{l}\text { - } 100 \% \text { têm EPI recebidos da empresa, que são substituídos } \\
\text { continuamente }\end{array}$} \\
\hline & \multicolumn{2}{|c|}{$-38,46 \%$ usam impreterivelmente os EPI } \\
\hline & $\begin{array}{l}\text { - } 61,54 \text { informam que nem } \\
\text { sempre usam EPI }\end{array}$ & $\begin{array}{l}\text { principais motivos: } \\
-53,85 \% \text { por esquecimento } \\
-\quad 46,15 \% \text { pelas condições } \\
\text { climáticas (fatores externos) }\end{array}$ \\
\hline Normas de segurança & \multicolumn{2}{|c|}{$\begin{array}{l}\text { - 19,23\% afirmam seguir integralmente normas e procedimentos } \\
\text { - 80,77\% afirmam obedecer em parte por incorporar métodos } \\
\text { próprios que às vezes fogem dos treinamentos }\end{array}$} \\
\hline
\end{tabular}

Fonte: Elaborado pelos autores, 2020.

As principais fontes de tensão, fadiga e estresse identificadas no ambiente de trabalho são calor excessivo durante o trabalho $(16,67 \%)$, pouco tempo para pausas e possível demissão (ambos com 14,28\%), salário baixo ao considerar a atividade realizada, falta de cooperação entre os colegas de trabalho, falta de oportunidade de ser promovido e cumprimento de horas extras mesmo com remuneração (todos com 12,70\%). Esses índices estão ilustrados no Gráfico 1:

Gráfico 1 - Principais fontes de tensão, fadiga e estresse no ambiente de trabalho

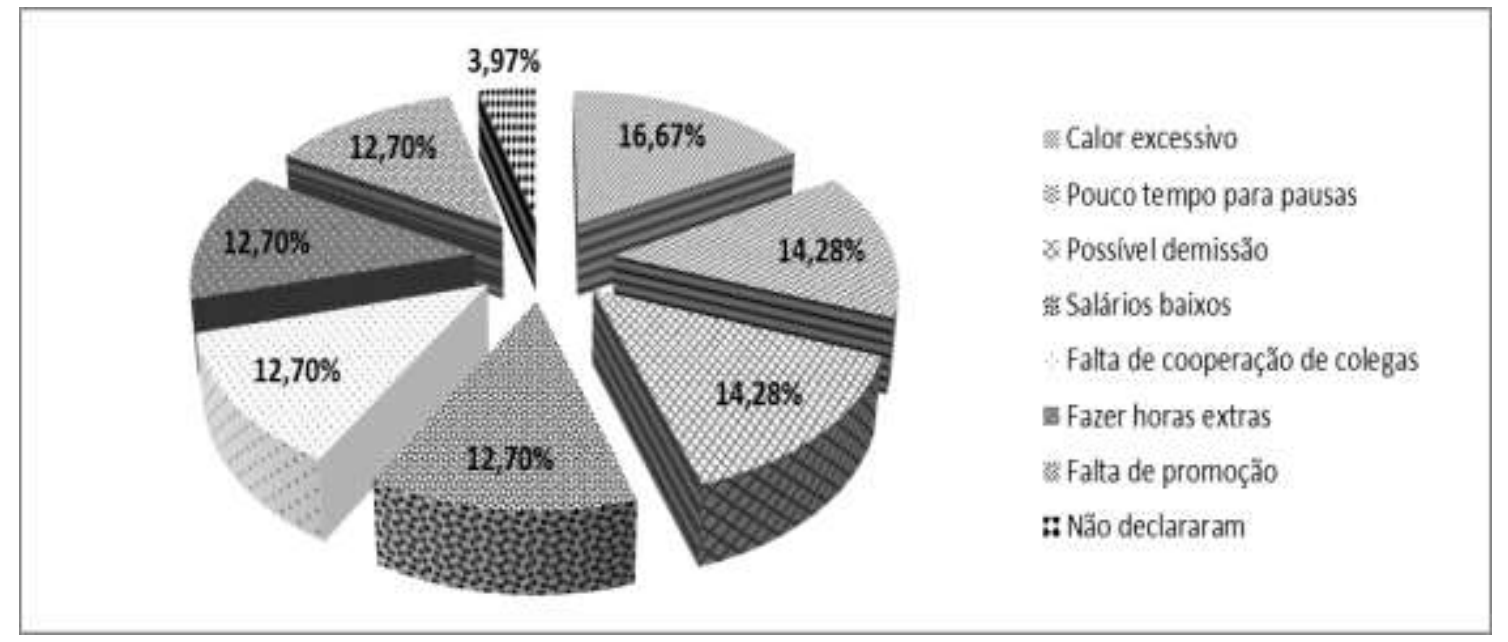

Fonte: Elaborado pelos autores, 2020.

Entre o que mais desagrada os trabalhadores, alguns pontos foram destacados: não haver uma divisão adequada de atividades, o que sobrecarrega o trabalhador em caso de erros, por falta de companheirismo dos colegas; não conseguir atender ao cliente necessitado do serviço; ingratidão de clientes atendidos; dificuldades encontradas no ambiente de trabalho devido ao isolamento na zona rural; rotina; distância da família.

Conforme relatado pelos empregadores, o maior número de advertências verbais tem como causa o não uso de EPI, mais especificamente luvas e óculos de proteção, destacando-se como o comportamento de risco mais frequente. É importante ressalvar que retirar os óculos e as luvas, assim como abrir os botões da camisa e usar inadequadamente os EPI, são práticas de risco aparentemente simples e inofensivas, mas expõem o trabalhador a riscos inesperados.

As luvas de vaqueta, confeccionadas em couro, são adequadas para o trabalho em altura, postes e estruturas metálicas, inclusive para atividade de puxar os fios da rede após a implantação dos postes, trabalho braçal realizado pelos trabalhadores em conjunto. As luvas protegem de cortes, arranhões e atrito, e por baixo delas, quando necessário, são utilizadas 
luvas de borracha, que requerem cuidados especiais para não danificar suas propriedades isolantes de eletricidade.

O uso de adornos como anéis, alianças e colares é expressamente proibido, segundo orientações da NR 32 do Ministério do Trabalho e Emprego (Brasil, 2005), pois pode deixar parte dos dedos ou o pescoço preso a algum objeto e gerar acidentes, como cortes ou estrangulamento. Nos registros reunidos neste estudo, além do uso de colares confeccionados com peças de madeira, um funcionário estava com o uniforme entreaberto, suscetível a picadas de insetos e agressão solar.

Além das situações de comportamento de risco supracitadas, há ainda casos em que os trabalhadores se expõem inadequadamente a partes móveis de máquinas, equipamentos e estruturas pesadas. Durante a pesquisa e nas fotos disponibilizadas pela empresa, as atitudes inseguras encontradas foram:

a. contato direto com o objeto (poste) sem instrumentos de ajuda: como o peso do poste é incompatível com a força do trabalhador, qualquer desiquilíbrio ou movimentação inesperada pode machucá-lo, e um desprendimento pode provocar graves acidentes.

b. distração do profissional: quando se coloca o corpo em posição de relaxamento, há perda de boa parte dos reflexos, o que torna os movimentos mais lentos.

c. uso do objeto como descanso do braço: ao usar um objeto em estado instável como apoio, por mais suave que seja o ato, a imposição de uma pressão sobre ele poderá promover desequilíbrio ou manobra que o lance sobre o corpo de quem está próximo.

d. posição de risco: ao se movimentar e ficar entre o poste e o caminhão, o trabalhador pode ficar preso entre eles se o guindaste que puxa o poste sofrer instabilidade.

De acordo com os gestores da empresa, os empregados admitidos recebem treinamentos sobre a maneira adequada de realizar suas atividades, a obrigatoriedade e a importância do uso de EPI. No entanto, muitas vezes as instruções não são seguidas, seja por não perceber o perigo, indisciplina ou esquecimento, o que fica evidente nos registros.

São vários os casos de advertências aplicadas aos trabalhadores por comportamentos de risco. No período de 2014 a 2019, foram registradas 13 advertências por escrito, o que é bastante significativo por se tratar de uma empresa de pequeno porte com um pequeno número de colaboradores (26). As advertências não são interessantes para o trabalhador, e, uma vez oficializadas, ficam registradas na Carteira de Trabalho por toda a vida ativa.

$\mathrm{Na}$ construtora, três avisos verbais geram ao empregado inconformidade. É importante lembrar que três registros na Carteira de Trabalho permitem uma demissão por justa causa. Segundo os relatórios de advertências, a maioria delas tem como motivo a não utilização de EPI, conforme exposto no Quadro 4:

Quadro 4 - Registros de advertências formais aplicadas aos funcionários de 2008 a 2014

\begin{tabular}{|c|c|c|}
\hline Funcionário & Função & Motivo da advertência \\
\hline \multirow{3}{*}{ MSO } & \multirow{3}{*}{ Motorista munckeiro } & Executado o trabalho sem utilizar EPI e EPC. \\
\hline & & $\begin{array}{l}\text { Manutenção do caminhão munck por conta própria e } \\
\text { sem requisição fornecida pelo escritório. }\end{array}$ \\
\hline & & Atraso sem justificativas. \\
\hline \multirow[b]{2}{*}{ AFS } & \multirow[b]{2}{*}{ Eletricista encarregado } & Executado o trabalho sem utilizar EPI e EPC. \\
\hline & & $\begin{array}{l}\text { Não respeitar as normas de segurança do trabalho e não } \\
\text { usar EPI. }\end{array}$ \\
\hline GSL & Auxiliar de montagem & Não utilização de EPI - óculos de proteção. \\
\hline WMF & Auxiliar de montagem & Não utilização de óculos apropriados para a função. \\
\hline JCS & Operador/motorista & $\begin{array}{l}\text { Não cumprimento dos procedimentos de segurança ao } \\
\text { utilizar o remanejamento de dois postes com o mesmo } \\
\text { estopo. }\end{array}$ \\
\hline JPA & Montador de rede & $\begin{array}{l}\text { Não cumprimento das Normas de Segurança Obrigatória } \\
\text { de seu conhecimento e não uso de EPI - óculos de } \\
\text { segurança. }\end{array}$ \\
\hline LJB & Auxiliar de operador & $\begin{array}{l}\text { Prestar serviço à empresa sem condições físicas e } \\
\text { psicológicas, colocando sua vida e a de seus colegas em }\end{array}$ \\
\hline
\end{tabular}




\begin{tabular}{|c|c|c|c|}
\hline & & \multicolumn{2}{|l|}{ risco (alcoolizado). } \\
\hline RNP & Auxiliar de montagem & \multicolumn{2}{|c|}{$\begin{array}{l}\text { Conduzir veículo da empresa sem autorização e } \\
\text { alcoolizado. }\end{array}$} \\
\hline WVS & Auxiliar de montagem & \multicolumn{2}{|c|}{$\begin{array}{l}\text { Sair do alojamento sem comunicar o encarregado da } \\
\text { equipe e fazer uso de bebida alcoólica no local de } \\
\text { trabalho. }\end{array}$} \\
\hline JCA & Montador de Rede & \multicolumn{2}{|c|}{ Não utilização de óculos apropriados para a função. } \\
\hline $\begin{array}{l}\text { Síntese da } \\
\text { advertências }\end{array}$ & \multicolumn{2}{|c|}{$\begin{array}{l}\text { - 53,85\% relacionadas ao não uso de EPI e/ou EPC } \\
\text { - 23,08\% relacionadas a embriaguez no trabalho } \\
\text { - } 15,38 \% \text { relacionadas ao não cumprimento de } \\
\text { procedimentos de segurança } \\
-7,69 \% \text { relacionadas a falta de comprometimento }\end{array}$} & $\begin{array}{l}\text { - } 92,31 \% \text { são comportamento } \\
\text { de risco } \\
\text { - } 7,69 \% \text { não se enquadram } \\
\text { como comportamento de risco }\end{array}$ \\
\hline
\end{tabular}

Fonte: Elaborado pelos autores, 2020.

As atividades que exigem contato com energia elétrica devem ser realizadas rigidamente de acordo com os procedimentos de segurança, devido ao risco de graves acidentes. Nos serviços de eletrificação rural, além do contato com energia elétrica, há intenso manuseio de materiais e maquinários pesados, e qualquer procedimento inadequado pode comprometer a segurança de todos os envolvidos na operação. Exemplo disso é o remanejamento de dois postes com o mesmo estopo.

De acordo com os gestores, a aplicação de advertência, além de servir como penalidade, é um mecanismo utilizado para diminuir a incidência de trabalhadores expostos por conta própria a um risco de acidente capaz de gerar graves consequências tanto ao colaborador quanto aos empresários.

Ao analisar as entrevistas dos trabalhadores, verificou-se que apenas 19,23\% deles declaram obedecer integralmente aos procedimentos de segurança e somente $38,46 \%$ usam impreterivelmente os EPI. Os registros da empresa apontam que as principais causas desses acidentes estão relacionadas a aspectos comportamentais: falta de atenção (três casos), não cumprimento dos procedimentos de segurança (dois casos) e não utilização de EPI (um caso).

O Quadro 5 apresenta algumas características dos acidentes:

Quadro 5 - Tipos de acidentes registrados na construtora

\begin{tabular}{|c|c|c|c|c|}
\hline Ano & Trabalhador & Idade & Descrição & Causa primária \\
\hline 2008 & GSL & 19 & $\begin{array}{l}\text { Perfuração do olho esquerdo } \\
\text { (perda de } 4 \% \text { da visão) }\end{array}$ & $\begin{array}{l}\text { Não uso de EPI (óculos de } \\
\text { segurança). }\end{array}$ \\
\hline 2009 & JPA & 47 & Queda de escada & Falta de atenção. \\
\hline 2010 & JCA & 40 & Choque elétrico & $\begin{array}{lll}\text { Não } & \text { cumprimento } & \text { dos } \\
\text { procedimentos de segurança. }\end{array}$ \\
\hline 2011 & JCS, RG & $\begin{array}{l}40 \\
28\end{array}$ & Tombamento do caminhão & $\begin{array}{l}\text { Perda de controle da direção - pneu } \\
\text { dianteiro estourado após o choque } \\
\text { numa depressão na estrada. }\end{array}$ \\
\hline 2011 & $\mathrm{CD}$ & 23 & Perfuração da mão direita & Falta de atenção. \\
\hline 2013 & WM & & Quebra de um dedo & $\begin{array}{l}\text { Não cumprimento de procedimentos } \\
\text { de segurança. }\end{array}$ \\
\hline 2013 & GR & 30 & $\begin{array}{l}\text { Traumatismo craneano (óbito } \\
\text { imediato) }\end{array}$ & $\begin{array}{l}\text { Falta de atenção/fatalidade } \\
\text { caminhão ligado sem estar no ponto } \\
\text { morto. }\end{array}$ \\
\hline
\end{tabular}

Fonte: Elaborado pelos autores, 2020.

Considerando os cinco anos analisados (2014-2019), os casos de acidentes de trabalho por comportamento de risco acentuaram-se nos quatros primeiros anos de atuação da empresa do período analisado. O primeiro caso ocorreu em $2008 \mathrm{com}$ um dos auxiliares de montagem, GSL, ao manusear um cabo de alumínio. A causa imediata (que contribuiu diretamente), segundo os registros da empresa, foi o não uso dos óculos de proteção.

De acordo com o dossiê da empresa, na época o trabalhador relatou: 
fui arrumar o cabo de alumínio que estava em cima do caminhão na bobina, peguei o cabo e dei a volta por cima da minha cabeça, com o objetivo de enrolá-lo na bobina, e a ponta do cabo atingiu meu olho esquerdo [...]. (GSL - relato de dossiê da construtora)

$\mathrm{Na}$ entrevista sobre o motivo do acidente, o colaborador relatou:

quando cheguei ao alojamento, fui direto à cozinha para beber água, deixei os óculos em cima da mesa e voltei para arrumar os materiais e ferramentas que estavam dentro do caminhão; foi nessa hora que aconteceu o acidente com meu olho. (GSL - comunicação pessoal, julho de 2014)

A função do trabalhador envolve as atividades de limpeza da área com vegetação para viabilizar a construção da rede, perfuração manual de vala com o uso de cavadeira, bem como auxiliar na montagem e na manutenção de postes e instalações de equipamentos, o que exige, pela natureza das atividades, o uso de luvas de raspa, óculos de proteção, capacete e botina de segurança. Conforme depoimento dos gestores, o referido trabalhador tinha recebido todos os treinamentos e EPI.

Sabe-se que o uso de EPI não isenta o trabalhador de sofrer acidentes, mas evita consequências graves. $O$ fato de o colaborador não ter utilizado os óculos de proteção propiciou a lesão do seu olho esquerdo, resultando na perda de $4 \%$ de sua visão. $\mathrm{Na}$ entrevista, GSL declarou que o acidente ocorreu enquanto arrumava e guardava os materiais de trabalho, por volta das $13 \mathrm{~h} 30$ do dia que antecedia sua folga. Afirmou ainda não estar preocupado ou passando por algum problema no momento do acidente, embora estar afastado de sua família e sem vê-la há algum tempo o afligia, por isso estava estressado com o acúmulo de trabalho e apressado para terminar suas atividades e voltar para casa.

O trabalhador diz que sempre faz uso do EPI, no entanto, devido à pressa para concluir sua atividade e à confiança de que jamais sofreria um acidente naquele momento, não se importou em usá-lo. Quando perguntado sobre outros fatores que possam ter interferido nesse tipo de comportamento, além de pressa e estresse, GSL apontou o cansaço que sentia no momento e a falta de atenção.

Mediante as consequências já apontadas, o colaborador complementou que o acidente também proporcionou transtornos para sua família, quando da notícia do ocorrido, devido à distância e à enorme preocupação. Seu afastamento refletiu ainda na sua situação financeira, pois o salário que recebeu do Instituto Nacional do Seguro Social (INSS) foi inferior, diferença relacionada aos benefícios pagos por índice de produtividade e hora extra.

O segundo caso de acidente ocorreu em 2014 com JPA, montador de rede, e não teve a causa imediata identificada, apenas a causa básica descrita como falta de atenção resultando em fratura da extremidade distal do rádio (punho). $\mathrm{O}$ acidente foi descrito da seguinte forma pelo acidentado, conforme registrado no dossiê da empresa: "quando estava descendo da escada após ter feito a instalação do beiral da casa, pisei fora do degrau e caí, e, para sustentar meu corpo, levei a mão direita ao chão" (JPA - relato de dossiê da construtora).

A ordem de serviço de segurança e medicina do trabalho direcionada a todos os montadores de rede prevê o trabalho com escadas e apresenta todos os procedimentos de segurança a serem seguidos. Nos registros do acidente, os procedimentos de segurança foram obedecidos e não houve interferências físicas externas, apenas falta de atenção, que está estritamente ligada ao aspecto comportamental.

O funcionário JPA, em entrevista, aponta que a causa do acidente foi em pequena parte falta de atenção, pois o próprio trabalho é perigoso, e afirma que não estava passando por nenhum problema de saúde, financeiro, familiar, de perseguição, que não estava preocupado ou emocionalmente estável, mas "talvez com um pouco de pressa". Como em outros casos semelhantes, a pressa foi um fator determinante para a ocorrência.

As respostas desse colaborador são semelhantes às de $C D$, acidentado em 2016 que teve a mão perfurada. Com exceção da pressa, este destacou o fator climático ao afirmar que o calor "atrapalha os sentidos", ou seja, "rouba a pessoa" e a deixa dispersa. Os dois afirmam sempre ter feito uso de EPI. 
O terceiro caso aconteceu em 2015 e é de um acidente por não cumprimento dos procedimentos de segurança. Conforme o relato, no final da jornada de trabalho, o trabalhador JCA, com pressa para terminar suas atividades e devido ao tempo chuvoso, não realizou os procedimentos de segurança para a energização de rede e subiu no poste usando apenas esporas, botas e luvas, sofrendo um choque por indução elétrica ao manusear a chave.

O cabo de rede é um condutor que pode receber carga simplesmente do vento ou de nuvens carregadas, e, de acordo com a ordem de serviço de segurança e medicina do trabalho, na atividade de energização, é proibido qualquer serviço na rede que gere risco de choque por indução elétrica. $O$ fato de 0 trabalhador não seguir esse procedimento de segurança por realizar a atividade em tempo chuvoso e ainda não fazer uso de todos os EPI (cinto de segurança) foi um ato extremamente arriscado que resultou em um acidente de trabalho.

A descarga elétrica resultou em queimaduras nas mãos, nos pés e no saco escrotal, pois a corrente atravessou o corpo do trabalhador a ponto de estourar a bota de segurança. Devido a essas consequências, houve necessidade de afastamento do colaborador por um ano, recebendo salário, cesta básica e auxílio médico, pois ainda estava em período de experiência sem ser registrado (responsabilidade assumida pela empresa).

Em janeiro de 2015, JCS, motorista que conduzia veículo com mais oito funcionários, sofreu um acidente. Após passar por uma ponte, o veículo teve o pneu dianteiro estourado devido ao choque em uma depressão na estrada, descendo uma ribanceira e tombando o veículo. Esse caso se caracterizou como um acidente de trajeto, gerando prejuízos à empresa de, em média, 10 mil reais com resgate e reparos, além de uma lesão, pois um colaborador RG (segundo motorista) teve sua costela fraturada, ficando afastado por 15 dias, ainda que sem danos maiores à qualidade de sua saúde.

O quinto acidente e segundo caso ocorrido em 2016, cuja vítima foi o trabalhador CD, teve como causa básica e imediata a falta de atenção. Uma das tarefas que compõem a base para a montagem de rede é o firmamento da haste de ferro no chão, que, de acordo com a descrição das atividades referentes ao cargo de auxiliar de montagem (função de CD), deve ser enterrada totalmente com o auxílio de um equipamento em forma de T chamado soquete.

Durante essa tarefa, o trabalhador aplicou força desnecessária no momento do encaixe da haste, e, mesmo fazendo uso do EPI adequado (luvas de raspa), houve a perfuração da mão direita, por isso, nesse caso, o equipamento de segurança apenas diminuiu a gravidade da lesão, gerando ainda um afastamento de oito dias.

O acidente ocorrido em 2017 também teve como causa o não cumprimento dos procedimentos de segurança. No auxílio ao remanejamento de um poste, o colaborador WM não utilizou a corda necessária para a movimentação deste, que é de suma importância para que o trabalhador não tenha contato direto e permaneça a, no mínimo, 1,5 m de distância.

O remanejamento é realizado com um guindaste, que, ao movimentar um dos postes que estava sendo erguido, prensou um dos dedos do trabalhador, que estava segurando com as mãos uma das extremidades. O acidente resultou em uma lesão (quebra de um dedo médio) e afastamento de 10 dias do trabalhador.

O último caso de acidente aconteceu ainda em 2013 e foi uma fatalidade que levou a óbito o trabalhador GR. O caso ocorreu durante uma manutenção no caminhão com a cabine vasculhada: o funcionário GR (encarregado), ao inspecionar a manutenção, posicionou-se entre a cabine e o pneu dianteiro (exposição ao risco de forma inconsciente) e solicitou que o funcionário WVS desse partida no veículo, o qual, por falta de atenção, o fez com marcha engatada. Nesse momento, o caminhão deu um solavanco para frente, batendo a cabine no teto do acampamento e fazendo com que ela voltasse e se fechasse sobre o funcionário, que veio a óbito imediato.

Após as entrevistas com os funcionários, ficou evidente sua compreensão quanto aos fatores que possam interferir em um acidente. Ao retratar os acidentes ocorridos, foi possível perceber que eles justificam para si mesmos os comportamentos de risco, ao explanarem repetidamente os motivos que os levaram a assumir esses comportamentos. 
Assim, nota-se que os colaboradores sabem dos riscos, porém, por se sentirem muito seguros do domínio que têm de sua tarefa, há muita autoconfiança, aliada a fatores externos como calor, cansaço, pressa e outros componentes ideais para a ocorrência de acidentes.

\section{Conclusão}

Comportar-se de maneira segura, a fim de preservar sua integridade física, deveria ser um ato instintivo, entretanto, os índices de acidentes registrados na construtora estudada são altos. Nesse sentido, revela-se a necessidade de adotar atitudes com início ainda na infância, começando em casa e chegando à educação básica formal, com ensinamentos de civilidade, higiene e sociabilidade, de modo que estes sejam tão naturais como se proteger de situações visivelmente inseguras, tornando-se característicos do indivíduo, como uma habilidade pessoal ou algo coletivo.

Este estudo possibilitou observar as limitações encontradas nos trabalhadores que ainda conservam comportamentos tidos como fatores de risco. Ao analisar os dados, foram identificados os principais comportamentos de risco dos trabalhadores sujeitos da pesquisa, como a execução das atividades laborais sem a utilização de EPI, especialmente luvas e óculos de proteção, sob efeito de bebida alcoólica e sem realizar procedimentos de segurança, com ênfase para a atividade de remanejamento de postes e o uso de adornos.

O fato de apenas $19,23 \%$ dos colaboradores obedecerem integralmente aos procedimentos de segurança e $38,46 \%$ usarem impreterivelmente os EPI já contribui para as evidências da quantidade expressiva de trabalhadores expostos a riscos de acidentes desnecessariamente, apenas por uma decisão pessoal.

Decisões dessa ordem são justificadas por motivos como esquecimento e condições climáticas, o que significa que há comportamentos com interferência de fator externo ligado às condições de trabalho. Essas atitudes, movidas também por autoconfiança e pressa, assumem esse tipo de risco, que em algum momento agrava o bem-estar da saúde física da pessoa e, em outros casos, deixa sequelas irreversíveis ou até mesmo leva ao óbito.

Uma característica comum entre os acidentes é a falta de atenção. É improvável que um trabalhador possa ficar absolutamente em alerta durante todas as oito horas de trabalho, e os momentos fatídicos são observados no período de dispersão destes, acentuando o valor das pausas durante a atividade laboral para redobrar a atenção e a disposição para o trabalho.

A perda da qualidade de saúde do ser humano é a maior fonte de preocupação desses comportamentos, mas as consequências dos acidentes acarretadas para a empresa, principalmente no âmbito financeiro, também refletem na produção, além de gerar um desgaste psíquico para os outros trabalhadores, os encarregados e os gestores.

A partir dos resultados da pesquisa, constata-se que é necessário intensificar os programas de segurança com foco no comportamento dos trabalhadores, pois há influência deste na ocorrência dos acidentes. Sugere-se a utilização da auditoria comportamental como método para a identificação das não conformidades relativas ao comportamento, conscientizando as pessoas para a correção de desvios que as expõem a riscos de acidentes.

\section{Referências}

Acevedo, Claudia R.; Nohara, Jouliana J. (2009). Monografia no Curso de Administração: guia completo de conteúdo e forma. 3. ed. São Paulo: Atlas.

Andrade, Alessandro L.; de Oliveira, Manoela Z.; Hatfiel, Elaine (2017). Conflito trabalhofamília: um estudo com brasileiros e norte-americanos. Revista Psicologia Organizações e Trabalho, v. 17, n. 2, p. 106-113.

Areosa, João; Veloso Neto, Hernâni A.; Arezes, Pedro (2012). Impacto social dos acidentes de trabalho. Vila do Conde, PT: Civeri Publishing. 
Balassiano, Moisés; Botelho, Delane; Zouain Deborah M. (2006) Pesquisa Quantitativa em Administração. São Paulo: Atlas.

Barsano, Paulo R.; Barbosa, Rildo P. (2018). Higiene e segurança do trabalho. 2. ed. São Paulo: Editora Érica.

Baptista, Makilim N., Campos, Dinael C. (2016) Metodologia de Pesquisa em Ciências: Análise Quantitativa e Qualitativa. São Paulo: LTC.

Barbosa Filho, A.N. (2019) Segurança e Gestão Ambiental. 5. ed. São Paulo: Atlas.

Bedin, Barbara 2010). Prevenção de acidentes de trabalho no Brasil sob a ótica dos incentivos econômicos. Caxias do Sul: LTr.

Bendassolli, Pedro F.; Gondim, Sonia M.G. (2014) Significados, sentidos e função psicológica do trabalho: discutindo essa tríade conceitual e seus desafios metodológicos. Avances en Psicología Latinoamericana, v. 32, n. 1, 131-147.

Benevenuto, Rogério C.; Gomes, Robson S.; Barros, Sergio R.; Lima, Gilson B.A. (2013). Aspectos comportamentais da segurança do trabalho: relato e reflexões de experiências na aplicação de um programa de auditoria comportamental em uma empresa de construção naval. Resumos do Congresso Nacional de Excelência em Gestão. Rio de Janeiro: Universidade Federal Fluminense. Disponível em <http://www.inovarse.org/filebrowser/download/15567>. Acesso em: 12 dez 2019.

Bley, Juliana Z. (2011). Comportamento Seguro: a Psicologia da Segurança no Trabalho e a educação para a prevenção de doenças e acidentes. Disponível em https://docs.google.com/file/d/OB-

SJh5YBzFcwQXRmMkx0dFBUOVMwczJZaDJPOWZWdw/edit, Acesso em 05 jan 2020.

BRASIL (1978a). NR 4 - Serviços Especializados em Engenharia de Segurança e em Medicina do Trabalho. Disponível em http://trabalho.gov.br/images/Documentos/SST/NR/NR4.pdf, Acesso em 23 nov 2019.

BRASIL (1978b). NR 10 - Segurança em Instalações e Serviços em Eletricidade. Disponível em: <http://trabalho.gov.br/images/Documentos/SST/NR/NR-10-atualizada-2016.pdf>. Acesso em 15 nov 2019.

BRASIL (1991). Lei n. 8.213, de 24 de julho de 1991. Dispõe sobre os Planos de Benefícios da Previdência Social e dá outras providências. Disponível em <http://www.planalto.gov.br/ccivil_03/LEIS/L8213cons.htm>. Acesso em 21 nov 2019.

BRASIL (2005). Segurança e Saúde no Trabalho em Serviços de Saúde. Disponível em $<$ http://www.trabalho.gov.br/images/Documentos/SST/NR/NR32.pdf>. Acesso em 05 dez 2019, 2005.

BRASIL (2012a). AEPS 2010 - Anuário Estatístico da Previdência Social 2010. Brasília: Secretaria de Previdência. Disponível em http://www.previdencia.gov.br/dados-abertos/aeps2010-anuario-estatistico-da-previdencia-social-2010. Acesso em 17 dez 2019.

BRASIL (2012b). País gasta cerca de $R \$ 70$ bilhões com acidentes de trabalho. Portal do Brasil. Disponível em http://www.brasil.gov.br/saude/2012/04/acidentes-de-trabalho. Acesso em 17 dez 2019.

Celich, Kátia L.S.; Restelatto, Márcia (2008). Ambiente hospitalar: Espaço para a construção e crescimento do ser humano. Journal of Nursing UFPE On Line, v. 2, n. 4, p. 348 - 356.

Costa, Osmar S.; Lanzarini, Ricardo (2011). Estudo de caso sobre as condições de segurança dos Funcionários de base da empresa x no município de Anastácio/MS. Revista Administração em Diálogo, v. 13, n. 2, p. $63-87$.

DIEESE - Departamento Intersindical de Estatística e Estudos Socioeconômicos (2016). Anuário da Saúde do Trabalhador 2015. São Paulo: DIEESE. Disponível em $<$ https://www.dieese.org.br/anuario/2016/Anuario_Saude_Trabalhador.pdf $>$. Acesso em $16 \mathrm{dez}$ 2019.

DIEESE - Departamento Intersindical de Estatística e Estudos Socioeconômicos (2017). Anuário do Sistema Público de Emprego, Trabalho e Renda 2016: Livro 7 - Indicadores da Saúde do Trabalhador com base na Rais. São Paulo: DIEESE. Disponível em <https://www.dieese.org.br/anuario/2017/Livro7_Saude.pdf>. Acesso em 16 dez 2019.

Gil, Antônio C. (2017). Como Elaborar Projetos de Pesquisa. 6. ed. São Paulo: Atlas. 
Hair Junior, Joseph F.; Babin, Barry; Money, Arthur H.; Samouel, Phillip (2005). Fundamentos de Métodos de Pesquisa em Administração. Porto Alegre: Bookman.

Klein, Amarolinda Z.; Silva, Lisiane V.; Machado, Lisiane; Azevedo, Debora (2015). Metodologia de pesquisa em administração: uma abordagem prática. São Paulo: Atlas.

Martins, Roberto A.; Mello, Carlos H.P.; Trrioni, João B. (2014) Guia Para Elaboração de Monografia e TCC em Engenharia de Produção. São Paulo: Atlas.

Mattos, Ubirajara A.O.; Másculo, Francisco S. (2019) Higiene e Segurança do Trabalho. 2. ed. São Paulo: GEN LTC, p. 23-49.

Michel, Maria H. (2017) Metodologia e Pesquisa Científica em Ciências Sociais. 3. ed. São Paulo: Atlas.

Mota, Miríam C.Z. (2015) Psicologia aplicada em Segurança do Trabalho: destaque aos aspectos comportamentais e trabalho em equipe da NR-10 - avaliação dos fatores psicossociais da NR-35. 5. ed. São Paulo: LTR.

Nascimento, Elizabeth do; Coutinho, Ana C.A.M.; Andrade, Jéssica. E.; Mendonça, Lívia M.M. (2015). Adaptação transcultural da Workplace Deviance Scale (WDS) para o contexto brasileiro. Revista Psicologia Organizações e Trabalho, v. 15, n. 4, p. 384-396.

Nascimento, Filipe C.; Salim, Celso A. (2018) Política de prevenção de acidentes na construção civil: uma análise das práticas da inspeção do trabalho. Revista Psicologia Organizações e Trabalho, v. 18, n. 1, p. 299-305.

OIT - Organização Internacional do Trabalho (2013). Doenças profissionais são principais causas de mortes no trabalho - 2013. Disponível em http://www.fetecpr.org.br/doencasprofissionais-sao-principais-causas-de-mortes-no-trabalho/, Acesso em: 18 nov 2019.

Pepplow, Luiz A. Segurança do Trabalho. Curitiba: Base Editorial, 2010.

Sampieri, Roberto H.; Collado, Carlos F.; Lucio, Maria D.P.B. (2013) Metodologia de Pesquisa. 5. ed. São Paulo: Porto Alegre: Penso.

Santos, Sérgio V.M.; Macedo, Flávia R.M.; da Silva, Luiz A.; Resck, Zelia M.R.; Nogueira, Denismar A.; Terra, Fábio S. (2017). Acidente de trabalho e autoestima de profissionais de enfermagem em ambientes hospitalares. Revista Latino-Americana de Enfermagem, v. 25, p. 1-8.

Scaldelai, Aparecida V.; Dias, Cláudio A.; Milaneli, Eduardo; Oliveira, João B.C.; Bolognesi, Paulo R. (2012). Psicologia do Trabalho. Manual Prático de Saúde e Segurança do Trabalho. 2. ed. São Caetano do Sul: Editora Yendis.

Sekaran, Uma; Bougie, Roger (2016). Research Methods for Business: A skill-building approach. 7. ed. New York: Wiley.

Silva, Ana P.; Braga, Enilson S.; Ferreira, Alex F.; Carvalho, José T. (2017). Proposta de prevenção de acidentes: um foco em aspectos comportamentais. Revista Eletrônica TECCEN, v. 10, n. 1, p. 3-9.

Silva, Bernadete F.; França, Sérgio L.B. (2011). Contribuição da Análise da Percepção de Riscos do Trabalhador ao Sistema de Gestão de Segurança e Saúde do Trabalho. Resumos do Simpósio de Excelência em Gestão e Tecnologia, Resende: AEDB.

Simonelli, Angela P.; Jackson Filho, José M.; Vilela, Rodolfo A.G.; Almeida, Ilberto M. (2016). Influência da segurança comportamental nas práticas e modelos de prevenção de acidentes do trabalho: revisão sistemática da literatura. Saúde e Sociedade, v. 25, n. 2, p. 463-478.

Szabo Junior, Adalberto M. (2018) Manual de Segurança, Higiene e Medicina do Trabalho. São Paulo: Rideel.

Wictor, leda C.; Sievers, Reinhardt (2012). Atos Inseguros e Condições Inseguras em Empresas Madeireiras. In: Congresso de Engenharia de Produção da Região Sul - Produção Inovadora e Sustentada, 2012, Joinville. 2o CONEPRO - SUL Produção Inovadora e Sustentada.

Yin, Robert K. (2015). Estudo de Caso: Planejamento e Métodos. 5. ed. São Paulo: Bookman. 